Docent dr Ljubiša Vasov, dipl. inž. Saobraćajni fakultet,
Beograd

\section{OCENA BEZOTKAZNOG RADA VAZDUHOPLOVA}

UDC: 629.7 .017

Rezime:

Pouzdanost kao kompleksni pokazatelj kvaliteta funkcionisanja sistema, zavisno od njegove osnovne namene i uslova procesa eksploatacije, obuhvata različite karakteristike sistema. Uzimajući u obzir specifične funkcionalne zahteve vazduhoplova, koji se odnose, pre svega, na bezbednost leta, jedno od primarnih svojstava njihove pouzdanosti jeste bezotkaznost. U ovom radu, razmatranjem karakteristika stacionarnog procesa obnavljanja, ocenjena je verovatnoća bezotkaznog rada vazduhoplova tokom datog vremena trajanja leta $i$ analizom funkcije pouzdanosti utvrđene su donja i gornja granica verovatnoće bezotkaznog rada. Time je pokazana mogućnost praktične primene eksponencijalne raspodele pri razmatranju bezotkaznosti i prikazan je način definisanja indikatora pouzdanosti vazduhoplova.

Ključne reči: vazduhoplov, pouzdanost, bezotkaznost, indikatori pouzdanosti.

\title{
ESTIMATION OF AIRCRAFT FAILURE-FREE PERFORMANCE
}

Summary:

Reliability as complex indicator of system operation quality, in dependence on system basic purpose and conditions of exploitation process, involves different system characteristics. Regarding to the specific operational requirements of aircraft, mainly related to the flight safety, one of primary attributes of their reliability is failure-free performance. In this paper, by considering the stationary conditions characteristics of renewal process, estimation of probability for failure-free operation during a given flight time is done, and by analysis of reliability function, lower and upper limits of probability for failure-free operation are established. Thereby, possibility for practical application of exponential distribution for failure-free performance consideration is shown, and method of aircraft reliability indicators determination is represented.

Key words: aircraft, reliability, failure-free performance, reliability indicators.

\section{Uvod}

Savremena vazduhoplovna transportna sredstva, sa konstruktivnog i strukturalnog aspekta, predstavljaju veoma složene tehničke sisteme specifične funkcionalne namene, od kojih se zahteva veoma visok nivo pouzdanosti izvršenja zadatka. Posmatrano sa aspekta ocene pouzdanosti, osnovne karakteri- stike procesa eksploatacije vazduhoplova mogu se formulisati na sledeći način: - pri razmatranju problematike pouzdanosti vazduhoplov se može posmatrati kao obnovljiv sistem kratkovremenog dejstva, odnosno sa kratkim intervalom vremena ispunjavanja zadatka u odnosu na kalendarsko vreme eksploatacije;

- jedno od osnovnih svojstava pouzdanosti vazduhoplova jeste njegova 
bezotkaznost, koja se kvantitativno ocenjuje verovatnoćom bezotkaznog rada vazduhoplova tokom intervala korišćenja, odnosno trajanja leta;

- posmatrano kroz vremensku sliku procesa eksploatacije, vreme obnavljanja vazduhoplova je kratko u poređenju sa vremenom njegovog bezotkaznog rada, čime koeficijent gotovosti ne utiče bitno na nivo efektivnosti sistema. Efektivnost takvog sistema, u osnovi, zavisi od broja otkaza tokom datog perioda eksploatacije, odnosno od bezotkaznosti koja je izražena srednjim vremenom rada do otkaza.

Preduslovi za ostvarivanje prethodno navedenih karakteristika jesu izrazito visok nivo pogodnosti održavanja i preventivni karakter procesa održavanja vazduhoplova, kojim se obezbeđuje potpuno obnavljanje radne sposobnosti komponenti i sistema. Pri tome, izbor i analiza kriterijuma efektivnosti određene komponente ili sistema vazduhoplova obično se vrši na osnovu uticaja otkaza date komponente na bezbednost leta, i ukupnih posledica događaja koji su izazvani njenom nepouzdanošću.

\section{Ocena verovatnoće bezotkaznog rada vazduhoplova}

Vazduhoplov se može posmatrati kao obnovljiv sistem, čija se bezotkaznost ocenjuje verovatnoćom bezotka- znog rada tokom vremena ispunjavanja letnog zadatka $\left(t_{k}\right)$ od trenutka $(\tau)$, odnosno $u$ intervalu vremena korišćenja sistema $\left(\tau, \tau+t_{k}\right)$. Matematički model kojim se opisuje proces obnavljanja vazduhoplova pri oceni bezotkaznosti uključuje sledeće pretpostavke [1]:

- vreme potrebno za obnavljanje radne sposobnosti vazduhoplova može se izuzeti iz dalje analize, u kojoj se vremenski faktor ne razmatra preko kalendarskog vremena već preko naleta aviona, čime se posmatrani proces svodi na obnavljanje sa trenutnim vremenom obnavljanja. Ovakav slučaj je često zastupljen u praksi, jer kod najvećeg broja tehničkih sistema jedinica vremena rada sistema i jedinica vremena obnavljanja su različite [2];

- intervali naleta vazduhoplova između otkaza predstavljaju međusobno nezavisne slučajne veličine;

- posle obnavljanja vazduhoplov poseduje ista svojstva kao i pre otkaza, odnosno zakon raspodele verovatnoće naleta do otkaza ne zavisi od broja otkaza.

Momenti obnavljanja $\left(\tau_{1}, \tau_{2}, \tau_{3}, \ldots\right.$, $\tau_{\mathrm{n}}$ ) formiraju takav niz događaja koji nastaju jedan za drugim (sl. 1) u momentima vremena slučajno raspoređenim u posmatranom periodu, odnosno obrazuju slučajan tok događaja koji se naziva procesom obnavljanja [1].

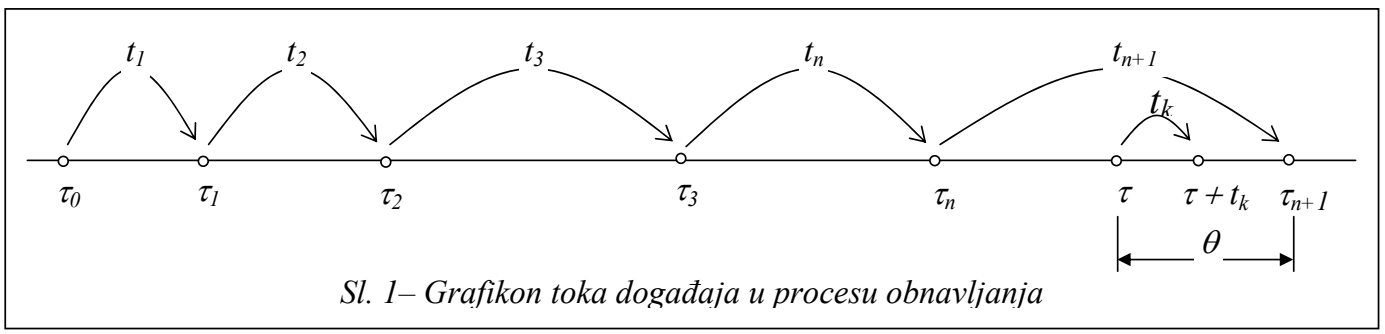


Od početnog trenutka $\left(\tau_{0}\right)$ posle naleta $\left(\mathrm{t}_{1}\right)$ vazduhoplova $\mathrm{u}$ trenutku $\left(\tau_{1}\right)$ dešava se prvi otkaz, pri čemu, prema prethodno usvojenim pretpostavkama, u istom momentu dolazi do obnavljanja radne sposobnosti vazduhoplova. Posle naleta $\left(\mathrm{t}_{2}\right)$ ponovo dolazi do otkaza $\mathrm{u}$ trenutku $\left(\tau_{2}\right) \mathrm{i}$ istovremeno do njegovog obnavljanja, itd. Skup momenata obnavljanja obrazuje proces obnavljanja sistema, pri čemu se u posmatranom slučaju potoci pojave otkaza i obnavljanja međusobno podudaraju.

Bezotkaznost vazduhoplova $\mathrm{u}$ datom procesu određena je verovatnoćom da tokom vremena $\left(t_{k}\right)$ korišćenja (leta) od trenutka $(\tau) \mathrm{u}$ intervalu $\left(\tau, \tau+\mathrm{t}_{\mathrm{k}}\right)$, neće doći do pojave otkaza. Prema usvojenim oznakama (sl. 1), tražena verovatnoća bezotkaznog rada $\mathrm{R}\left(\tau, \tau+\mathrm{t}_{\mathrm{k}}\right)$ može se izraziti u sledećem obliku, koji uključuje sve moguće ishode [1]:

$$
\begin{aligned}
& R\left(\tau, \tau+t_{k}\right)=P\left(t_{k}<\theta\right)= \\
& =\sum_{n=0}^{\infty} P\left(\tau_{n}<\tau ; \tau_{n}+t_{n+1}>\tau+t_{k}\right)
\end{aligned}
$$

Ukoliko do momenta $(\tau)$ nije bilo otkaza $(\mathrm{n}=0)$, tada se gornji uslovi bezotkaznog rada mogu izraziti nejednačinom: $\tau_{1}>\tau+t_{k}$. Uvođenjem promenljive $(x)$ umesto $\left(\tau_{\mathrm{n}}\right)$, dobija se: $\mathrm{x}+\mathrm{t}_{\mathrm{n}+1} \geq \tau+\mathrm{t}_{\mathrm{k}} \Rightarrow$ $t_{n+1} \geq \tau+t_{k}-x$, čime se jednačina (1) verovatnoće bezotkaznog rada $u$ datom intervalu $\left(\tau, \tau+t_{k}\right)$, za nestacionarni potok obnavljanja može prikazati u obliku [3]:

$$
\begin{aligned}
& R\left(\tau, \tau+t_{k}\right)=R\left(\tau+t_{k}\right)+ \\
& +\int_{0}^{\tau} R\left(\tau+t_{k}-x\right) \cdot h(x) d x
\end{aligned}
$$

gde je:

$\mathrm{h}(\mathrm{x})$ - gustina obnavljanja.

Posle velikog broja događaja, opisani proces obnavljanja postaje približno stacionaran, pri čemu je opravdano koristiti relacije asimptotskog procesa u kojem zakon raspodele vremena bezotkaznog rada vazduhoplova ne zavisi od naleta već samo od trajanja leta [3]:

$$
\begin{aligned}
& R\left(t_{k}\right)=\lim _{\tau \rightarrow \infty} R\left(\tau, \tau+t_{k}\right)=\frac{1}{T} \int_{t_{k}}^{\infty} R(x) d x= \\
& =-\frac{1}{T} \int_{\infty}^{t_{k}}[1-F(x)] d x
\end{aligned}
$$

gde je:

$\mathrm{T}$ - srednje vreme bezotkaznog rada.

Ispitivanje oblika funkcije $\mathrm{R}\left(\mathrm{t}_{\mathrm{k}}\right)$ moguće je izvršiti određivanjem prvog $\mathrm{i}$ drugog izvoda na osnovu prethodne relacije (3), za koje se dobijaju sledeći izrazi:

$$
\frac{d R\left(t_{k}\right)}{d t_{k}}=-\frac{1-F\left(t_{k}\right)}{T} ; \frac{d^{2} R\left(t_{k}\right)}{d t_{k}^{2}}=\frac{f\left(t_{k}\right)}{T} \geq 0
$$

Vrednost drugog izvoda ukazuje na to da funkcija $\mathrm{R}\left(\mathrm{t}_{\mathrm{k}}\right)$ ima konveksan oblik u odnosu na pravac vremenske (t) ose, odnosno funkcija $\mathrm{R}\left(\mathrm{t}_{\mathrm{k}}\right)$ nalazi se iznad tangente $\mathrm{u}$ tački $\left(t_{k}\right)$ i samim tim iznad tangente $u$ tački $\left(t_{k}=0\right)$. Koeficijent pravca tangente na krivu funkcije $R\left(t_{k}\right) u$ tački $\left(t_{k}=0\right)$, prema (4), jednak je: $R^{\prime}\left(t_{k}=0\right)=-1 / T$, čime je jednačina ove tangente data $\mathrm{u}$ obliku: $\mathrm{R}\left(\mathrm{t}_{\mathrm{k}}\right)=1-\mathrm{t}_{\mathrm{k}} / \mathrm{T}$.

Dobijena jednačina tangente ukazuje na veoma važnu ocenu donje granice vrednosti verovatnoće bezotkaznog rada $\mathrm{R}\left(\mathrm{t}_{\mathrm{k}}\right)$ : 


$$
R\left(t_{k}\right) \geq 1-\frac{t_{k}}{T}
$$

Gornja granica vrednosti pomenute funkcije $\mathrm{R}\left(\mathrm{t}_{\mathrm{k}}\right)$ određena je na osnovu opšte relacije funkcije pouzdanosti, za početak intervala $\left(\tau, \tau+t_{k}\right)$, gde je $\lambda\left(t_{k}\right)$ intenzitet otkaza na intervalu $(\theta)$ :

$R\left(t_{k}\right)=e^{-\int_{0}^{t_{k}} \lambda\left(t_{k}\right) d t_{k}} \leq e^{-\lambda(0)}$

Primenom relacije za intenzitet otkaza i prema jednačinama (3) i (4), može se napisati:

$$
\lambda\left(t_{k}\right)=-\frac{1}{R\left(t_{k}\right)} \cdot \frac{d R\left(t_{k}\right)}{d t_{k}}=\frac{1-F\left(t_{k}\right)}{\int_{t_{k}}^{\infty}[1-F(x)] d x}
$$

pri čemu se na početku intervala $(\tau, \tau+$ $\left.t_{k}\right)$ za $\left(t_{k}=0\right)$, prema prethodnoj relaciji, dobija:

$$
\lambda(0)=\frac{1}{\int_{0}^{\infty}[1-F(x)] d x}=\frac{1}{T}
$$

Za većinu modela promene intenziteta otkaza može se zaključiti da funkcija intenziteta otkaza obično ne zavisi od vremena ili ima monotono rastući karakter sa malim gradijentom, čime je potvrđena nejednačina (6). Time je, prema jednačini (7), određena gornja granica vrednosti verovatnoće bezotkaznog rada $\mathrm{R}\left(\mathrm{t}_{\mathrm{k}}\right)$ :

$$
R\left(t_{k}\right) \leq e^{-\frac{t_{k}}{T}}
$$

Prethodno datim nejednačinama (5) i (8) dobijena je dvostrana ocena verovatnoće bezotkaznog rada vazduhoplova, čija se vrednost nalazi između tangente $u$ tački $\left(t_{k}=0\right)$ i eksponencijalne funkcije:

$1-\frac{t_{k}}{T} \leq R\left(t_{k}\right) \leq e^{-\frac{t_{k}}{T}}$

\section{Približna vrednost verovatnoće bezotkaznog rada}

$\mathrm{Na}$ osnovu malog broja pojava otkaza, kao retkih događaja koji se mogu javiti tokom određenog intervala eksploatacije vazduhoplova i dovesti do gubitka njegove radne sposobnosti, moguća je samo približna ocena parametara pouzdanosti. Određivanje zakonitosti raspodele verovatnoće bezotkaznog vremena rada u razmatranom slučaju je praktično veoma teško, čime dvostrana ocena tražene verovatnoće $u$ inženjerskim proračunima i procenama dobija veliki značaj. Razvijanjem eksponencijalne funkcije u red, nejednačina (9) može se napisati u obliku:

$1-\frac{t_{k}}{T} \leq R\left(t_{k}\right) \leq 1-\frac{1}{1 !}\left(\frac{t_{k}}{T}\right)+$

$+\frac{1}{2 !}\left(\frac{t_{k}}{T}\right)^{2}-\frac{1}{3 !}\left(\frac{t_{k}}{T}\right)^{3}+\ldots$

Time je dobijena približna relacija za verovatnoću bezotkaznog rada u obliku:

$R\left(t_{k}\right) \approx 1-\frac{t_{k}}{T}$

čijom primenom se pravi greška $(\delta)$, koja ne prelazi vrednost: $\delta<\mathrm{t}_{\mathrm{k}}^{2} / 2 \mathrm{~T}^{2}$. 
Odnos vrednosti vremena korišćenja (trajanja leta) vazduhoplova $\left(t_{k}\right)$ sa srednjim vremenom između otkaza (T), koja su karakteristična za savremena vazduhoplovna prevozna sredstva, ukazuje na to da donja i gornja granica (9) ocene tražene funkcije verovatnoće bezotkaznog rada obrazuju vrlo usku oblast mogućih vrednosti. Drugim rečima, kada je eksponent $\mathrm{u}$ funkciji (8) približan ili manji od vrednosti $(0,01)$ donja i gornja granica se praktično poklapaju [4], i može se koristiti aproksimacija preko srednjeg vremena između otkaza (MTBF - Mean Time Between Failure):

$$
\begin{aligned}
& R\left(t_{k}\right)=e^{-\frac{t_{k}}{M T B F}} \approx 1-\frac{t_{k}}{M T B F} \Rightarrow \\
& \Rightarrow F\left(t_{k}\right) \approx \frac{t_{k}}{M T B F}
\end{aligned}
$$

Pri analizi bezotkaznosti i bezbednosti vazduhoplova uglavnom se radi sa veoma malim intenzitetima otkaza i relativno kratkim intervalima korišćenja, čime je primena date metode određivanja $\mathrm{R}\left(\mathrm{t}_{\mathrm{k}}\right)$ i $\mathrm{F}\left(\mathrm{t}_{\mathrm{k}}\right)$ opravdana. Prikazana ocena verovatnoće bezotkaznog rada vazduhoplova praktično je svedena na primenu eksponencijalne raspodele, koja se zbog svojstva odsustva posledica teorijski tačno ostvaruje za sisteme u kojima nema procesa trošenja tokom vremena.

Međutim, eksponencijalnu raspodelu je opravdano koristiti kod svih složenih sistema koji se sastoje od velikog broja visoko pouzdanih elemenata [5], u kojima procesi trošenja i starenja protiču sporo i mogu se zanemariti u relativno kratkim intervalima korišćenja [1], posebno ukoliko je izražen uticaj profilaktičkog karaktera održavanja, kao što je to slučaj sa vazduhoplovima. Treba naglasiti da se prema dosadašnjim iskustvima, stečenim na održavanju različitih mehaničkih i elektronskih sistema, u praksi može javiti ukupno šest različitih modela [6] promene intenziteta otkaza tokom veka trajanja sistema (sl. 2).

Model (A) jeste klasičan model, poznat pod nazivom kriva kade, koji sadrži skoro sva karakteristična područja promene intenziteta otkaza tokom veka trajanja sistema, prisutna u većini ostalih modela. Model (B) karakteriše se skoro konstantnim ili polako rastućim intenzitetom otkaza na početku eksploatacije, a zatim završava povećanim intenzitetom usled istrošenosti i starenja, slično kao u modelu (A). Prema modelu (C) celokupni vek trajanja sistema je praćen laganim
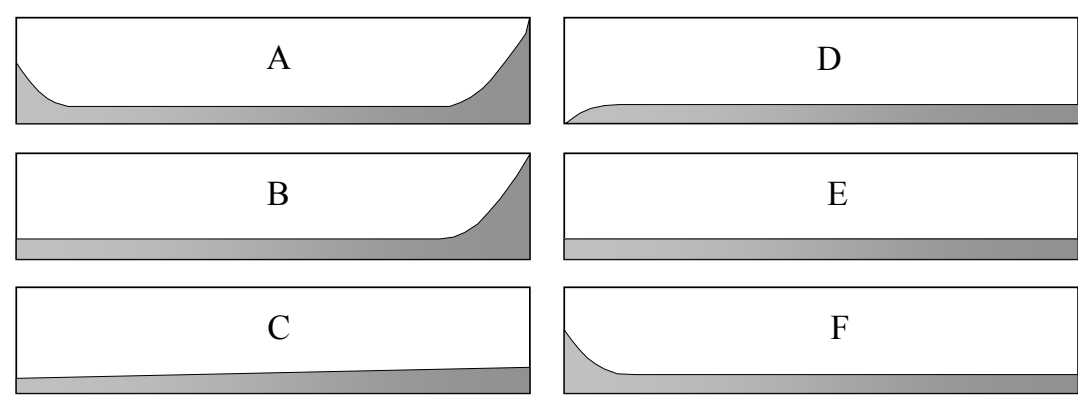

Sl. 2 - Postojeći modeli promene intenziteta otkaza tokom veka trajanja sistema 
i postepenim povećanjem intenziteta otkaza, koje nema posebno izražene intervale nagle promene gradijenta. Model (D) prikazuje nizak nivo intenziteta otkaza sistema na početku eksploatacije, kada je sistem nov ili malo korišćen, koji postepeno raste do neke približno konstantne vrednosti. Model (E) ima približno konstantan nivo intenziteta otkaza tokom veka trajanja, što je tipična osobina slučajnih otkaza. Model $(F)$ počinje povećanim intenzitetom otkaza sistema, slično modelu (A), koji se postepeno smanjuje do nekog približno konstantnog ili blago rastućeg nivoa.

Primera radi, istraživanja sprovedena na civilnim vazduhoplovima ukazuju da se prema modelu (A) ponaša $4 \%$ komponenti, prema modelu (B) do $2 \%$, modelu (C) oko 5\%, prema modelu (D) do $7 \%$ komponenti, modelu (E) približno $14 \%$ i modelu $(\mathrm{F})$ ne više od $68 \%$. Ovakva raspodela pojedinih oblika ponašanja sistema tokom veka trajanja nije ista za druge vidove tehničkih sistema. Međutim, može se uočiti opšta tendencija da sa povećanjem složenosti sistema sve veći doprinos pripada modelima (E) i (F). Time se, na osnovu modela promene intenziteta otkaza (sl. 2), može uočiti da tokom eksploatacije najveći deo vremena pripada periodu sa približno konstantnim ili blago rastućim intenzitetom otkaza, odnosno za dati interval može se usvojiti: $\lambda(t) \approx$ const.

\section{Koeficijenti pouzdanosti vazduhoplova}

Pri određivanju pokazatelja pouzdanosti komponenti i sistema vazduhoplova početni ulazni podaci jesu ukupno radno opterećenje razmatranog skupa komponenti i ukupan broj događaja (otkaza) koji su vezani za dati skup i interesantni za pouzdanost, u posmatranom kalendarskom periodu eksploatacije. Jedan od osnovnih statističkih pokazatelja pouzdanosti jeste srednje vreme rada $\left(T_{j}\right)$ po j-tom događaju:

$T_{j}=\frac{\sum_{i=1}^{n} t_{i}}{N_{j}}$

gde je:

$\mathrm{n}$ - ukupan broj komponenti u razmatranom skupu (floti aviona),

$t_{i}$ - vreme rada $\mathrm{i}$-te komponente $\mathrm{u}$ datom kalendarskom periodu, $\mathrm{i}$

$\mathrm{N}_{\mathrm{j}}$ - broj j-tih događaja interesantnih za pouzdanost, u posmatranom periodu.

Značenje srednjeg vremena $\left(T_{j}\right)$ prema izrazu (13) približava se matematičkom očekivanju vremena rada do pojave datog događaja, koje karakteriše dati skup, samo pri analizi velike grupe istih komponenti. Prethodna činjenica ukazuje na to da vreme $\left(T_{j}\right)$ predstavlja srednju karakteristiku pouzdanosti komponenti i sistema, sa različitim stepenima odrađenog resursa. Međutim, u mnogim praktičnim zadacima veličina $\left(\mathrm{T}_{\mathrm{j}}\right)$ u potpunosti određuje potok događaja interesantnih za pouzdanost, koji su vezani za dati tip komponenti i mogu se tretirati kao oblik otkaza posmatrane komponente.

Pomenuti način kvantifikacije pouzdanosti, za određeni kalendarski period, često se u praksi realizuje preko odgovarajućih koeficijenata pouzdanosti $\left(K_{j}\right)$, koji prikazuju broj j-tih događaja koji, u stvari, predstavljaju ispoljavanje nepouzdanosti komponente tokom procesa eks- 
ploatacije, na 1000 odgovarajućih jedinica rada date komponente:

$$
K_{j}=\frac{1000}{T_{j}}
$$

Smanjenje koeficijenta razmatranih događaja, datog prema prethodnoj relaciji (14), karakteriše povećanje pouzdanosti komponente ili sistema, i obično se koristi promena $\left(\mathrm{K}_{\mathrm{j}}\right) \mathrm{i}\left(\mathrm{T}_{\mathrm{j}}\right)$ tokom kalendarskog vremena eksploatacije, pri analizi dinamike promene pouzdanosti komponente. Prikazani jednostavni statistički pokazatelji omogućavaju rešavanje različitih zadataka povezanih sa problematikom određivanja verovatnoće ispunjavanja funkcije cilja i ocene efektivnosti sistema vazduhoplova. Treba napomenuti da se kvantifikacija pouzdanosti u sličnom obliku, preko srednjeg ili godišnjeg intenziteta otkaza (Average or Annual Failure Rate - AFR), primenjuje i kod drugih tipova tehničkih sistema [7] [8].

\section{Zaključak}

Visok nivo pouzdanosti današnjih vazduhoplovnih prevoznih sredstava i činjenica da otkazi koji dovode do gubitka radne sposobnosti vazduhoplova predstavljaju retke događaje, ukazuju na to da određivanje zakona raspodele vremena leta aviona do otkaza predstavlja veoma težak zadatak. Time dvostrana ocena funkcije verovatnoće bezotkaznog rada može imati veliki značaj. Prikazanom analizom funkcije pouzdanosti i utvrđivanjem donje i gornje granice verovatnoće bezotkaznog rada pokazana je moguć- nost praktične primene eksponencijalne raspodele pri razmatranju bezotkaznosti. Pored toga, dato je praktično značenje statističkih pokazatelja, koji se odnose na karakteristične događaje vezane za pouzdanost i prate tokom eksploatacije vazduhoplova.

Uobičajena praksa praćenja pouzdanosti flote, kod većine vazduhoplovnih kompanija, sastoji se u sistematskom registrovanju podataka bitnih za pouzdanost, koji se obično prikazuju u obliku mesečnih, polugodišnjih i godišnjih izveštaja. Sadržaj pomenutih podataka obuhvata događaje, kao što su: primedbe pilota i mehaničara, tehnički incidenti i kašnjenja, prevremena skidanja komponenti sa aviona, potvrđeni kvarovi, gašenje motora u letu, itd. $\mathrm{Na}$ osnovu broja registrovanih događaja u posmatranom kalendarskom periodu i ukupnog naleta flote aviona datog tipa u istom periodu, vrši se izračunavanje i praćenje konkretnih indikatora (koeficijenata) pouzdanosti.

Jedan od zadataka praćenja indikatora pouzdanosti jeste analiza trendova promene i registrovanje odstupanja stopa dešavanja događaja interesantnih za ocenu pouzdanosti flote, od normiranih vrednosti. Dobijeni izvorni podaci, kao komponente vremenske serije koja obično obuhvata mali broj događaja, u retkim slučajevima omogućavaju neposredan grafički prikaz pogodan za dalju analizu trendova promene. Veoma često, empirijski podaci imaju visok stepen rasturanja vrednosti, kombinovan sa određenim periodičnim modelom promene, koji, uglavnom, zavisi od sezonske promene dinamike korišćenja flote. Radi smanjenja stepena rasturanja i ublažavanja na- 
glih slučajnih promena vrednosti indikatora pouzdanosti, pri izračunavanju datih indikatora obično se u praksi koristi metoda pokretnih sredina.

Literatura:

[1] Анцелиович, Л. Л.: Надежность, безопасность и живучесть самолёта, Машиностроение, Москва, 1985.

[2] Knežević, J.: Osnove teorije obnavljanja, Održavanje Mašina i Opreme - OMO XXIV, Novinsko-izdavačka radna organizacija OMO, Beograd, broj 6-7, 1995, pp 310-323.

[3] Половко, А. М., Маликов, И. М., Жигарев, В. И., Зарудный, В. И.: Сборник задач по теории надежности, Советское радио, Москва, 1972.
[4] Training Program for Reliability Probability and Safety Analysis, Volume I-II-III-IV, Prepared for the Federal Aviation Administration Under Contract No. DOT FA75AC5123, Douglas Aircraft Company, August, 1981.

[5] Смирнов, Н. Н., Андронов, А. М., Владиморов, А. М., Лемин Ю. И.: Эксплуатационная недежность и режимы технического обслуживания самолётов, Транспорт, Москва, 1974.

[6] Mourbay, J.: Reliability - Centered Maintenance, Butterworth - Heinemann, Oxford, Second edition, 1997.

[7] Allmen, C. R., Lu M. W.: Sample size for Failure Detection and Reliability Demonstration, Proceedings Annual Reliability and Maintainability Symposium, IEEE Reliability Society, Atlanta, Georgia USA, January 26-28, 1993, pp 386-394.

[8] Elerath, J. G.: AFR: Problems of Definition, Calculation and Measurement in a Commercial Environment, Proceedings Annual Reliability and Maintainability Symposium, IEEE Reliability Society, Los Angeles, California USA, January 24-27, 2000, pp 71-76. 